\title{
Oral health related quality of life impact in dentistry
}

\begin{abstract}
In spite of its recent emergence over the past 30 years, oral health-related quality of life (OHRQoL) has important impact on the clinical practice of dentistry and dental research. OHRQoL is a multidimensional paradigm that involves a subjective evaluation of the individual's oral health, functional well-being, emotional well-being, expectations and satisfaction with care, and sense of self. It has been beneficial in relation to clinical research and health policies regulation. OHRQoL is an integral part of general health and well-being, World Health Organization (WHO) had considered Oral health related quality of life as an important section of the Global Oral Health Program (2003).
\end{abstract}

Volume 6 Issue 6 - 2017

\author{
Emad Eddin Alzoubi,' Racha Hariri, ${ }^{2}$ Nikolai \\ J Attard ${ }^{3}$ \\ 'Department of Dental Surgery, University of Malta, Malta \\ ${ }^{2}$ Department Department of Restorative Dentistry, University \\ of Malta, Malta \\ ${ }^{3}$ Dean of Faculty of Dentistry, University of Malta, Malta
}

Correspondence: Emad Eddin Alzoubi, Department of Dental Surgery, University of Malta, Medical School, Mater Dei Hospital, Block A, Level O, B’Kara Bypass, Msida MSD2090, Malta, Email alzoubiemad@gmail.com

Received: January 30, 2017 | Published: April 03, 2017

\section{Introduction}

\section{Historical overview}

The earliest discussion on quality of life in the ancient world is attributed to Herodotus who lived around $450 \mathrm{BC}$ during his visit in Egypt. Greek physicians applied different model of treatment which had a more holistic approach when compared to those in Egypt. At hospitals, drama and comedy plays were presented to the patients at hospital theatres; such an approach was viewed as being beneficial since it would alleviate and distract the patients from their symptoms while physicians would carry out their investigations. ${ }^{1}$ More recently the term "quality of life" emerged in the medical, dental and philosophical literature. It can be observed that in the 1960s and 1970s, as medical procedures advanced, researchers started including quality of life parameters to measure the outcomes beyond the classical treatment protocols. Later in the eighties specialists used the quality of life to formulate ethical and moral decisions for some severely disabled infants with respect to abortion issues. ${ }^{2}$ In the nineties researchers opened a new dimension of debate trying to relate patients' happiness and quality of life with a given treatment modality. ${ }^{2}$

\section{Oral health}

In the past three decades health was defined 'absence of illness' but this sentence is not truly valid. However the notion of "Well-being" is not that definition alone and the World Health Organization (WHO) in 1948, defined health as the following: "Health is a complete state of physical, mental, social wellbeing and not just the absence of the disease". Moreover, individual oral health is an important part of the general health and a crucial factor that impacts an individual quality of life. Oral health was defined by WHO in 2013 as "a state of being free from chronic mouth and facial pain, oral and throat cancer, oral sores, birth defects such as cleft lip and palate, periodontal disease, tooth decay and tooth loss, and other diseases and disorders that affect the oral cavity". Individuals with an increased concern about their facial appearance have lower quality of life standards and tend to isolate themselves from the society and any social interaction. ${ }^{3}$ Any disorder resulting in consequences on oral health may have huge impact on physical, social, and psychological wellbeing of a person. ${ }^{4}$

\section{Quality of life}

Individual quality of life (QoL) can be affected if the oral health is worsened. ${ }^{5}$ Quality of life is defined as the "perceptions of their position in life in the context of culture and value systems in which they live, and in relation to their goals, expectations, standards, and concerns" (WHO, 1995). Oral health related quality of life (OHRQOL) is a multidimensional construct that reflects on people's comfort when eating, sleeping, and engaging in social interaction; their self-esteem; and their satisfaction with respect to their oral health. ${ }^{3}$ Lately there has been a transition from traditional clinical dental/medical treatment outcome criteria which focus on diseases only such as (caries, periodontitis, gingivitis etc.) to more patient centered oral health delivery systems that focus on a person's social, emotional and physical experience. In other words it should address patient's health complaints and take in consideration the impact of the patient illness on his/her quality of life. ${ }^{6}$ Oral health related quality of life assists in making clinical decisions taking into account patients' desires and emotional and physical needs. ${ }^{4}$

\section{Health related quality of life and theoretical models}

Researchers have tried to elucidate how oral health is related to quality of life, ${ }^{5}$ and to understand the relationship between diagnosis and information from clinical examinations, person centered, selfreported health and health experiences. ${ }^{6}$ Many authors considered the impact of disease on an individual's quality of life, and tried to formulate theoretical models to explain the interrelation between health and sickness and quality of life. All of these models had attempted to explain the illness from multi-dimensional aspects; the following models can illustrate these interactions:

\section{Wilson and Cleary model (1995)}

Wilson and Cleary presented a conceptual model (Figure 1) that is composed of five aspects: physiological factors, symptom status, functional health, general health perceptions, and overall quality of life. It was proposed that physiological variables influence symptom statuses, which in turn influence functional health. The latter health affects general health perceptions that affect ultimately the overall quality of life. 


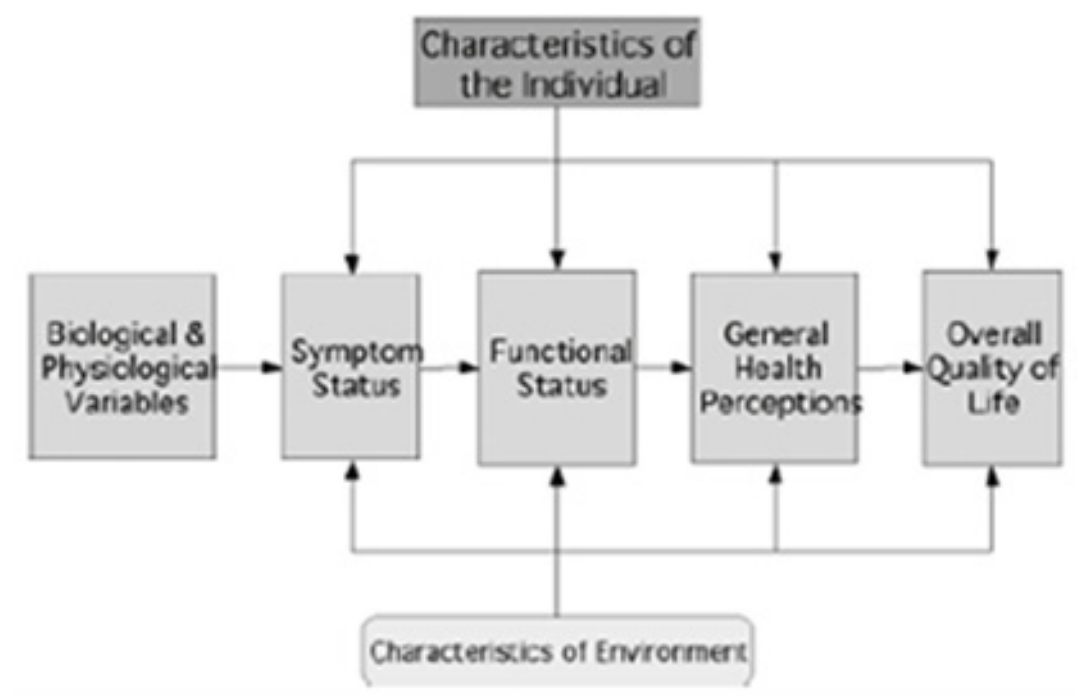

Figure I

II. Sischo and broder model for oral health related quality of life oral health related quality of life in children (20II)

The theoretical model proposed by Sischo and Broder combined biological, social, cultural and psychological factors. This model was adapted from the Wilson \& clearly model. It linked health status and/or clinical variables, functional status, oral-facial appearance, psychological status, OHRQoL, and overall QoL (Figure 2). In addition, this model also illustrated the effects of environmental factors, such as education, family income and structure, sociocultural factors and access to care on oral health perception and QOL. ${ }^{6}$

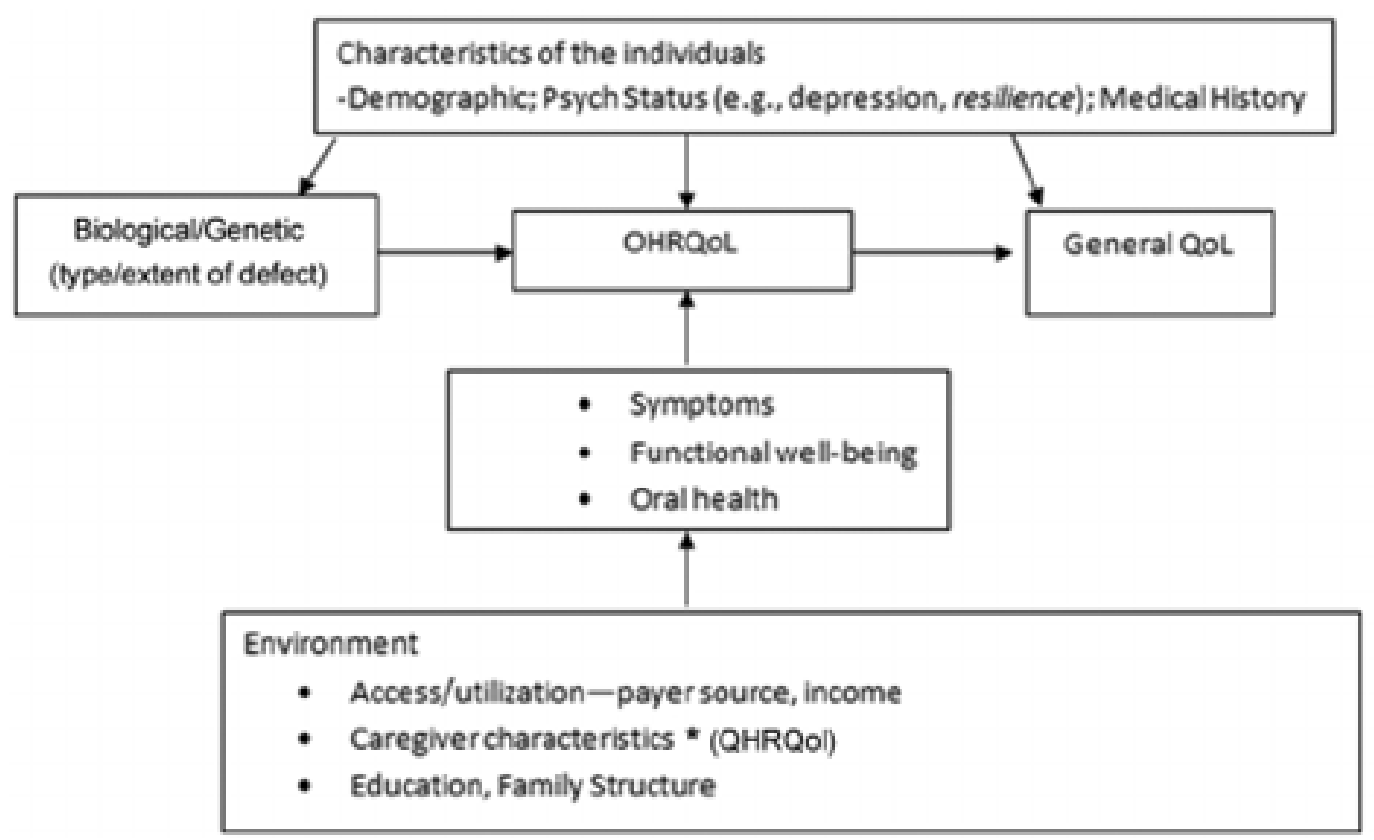

Figure 2

\section{Conceptual framework (Locker 1988)}

The conceptual framework described by (Locker, 1988) is based on the WHO classification of impairment, handicap and disability. It attempts to record the psychosocial and functional consequences of illness. For example edentulous people are considered impaired as consequence of tooth loss and will result in disability of individual to perform simple daily tasks such as eating or speaking (Figure 3). 


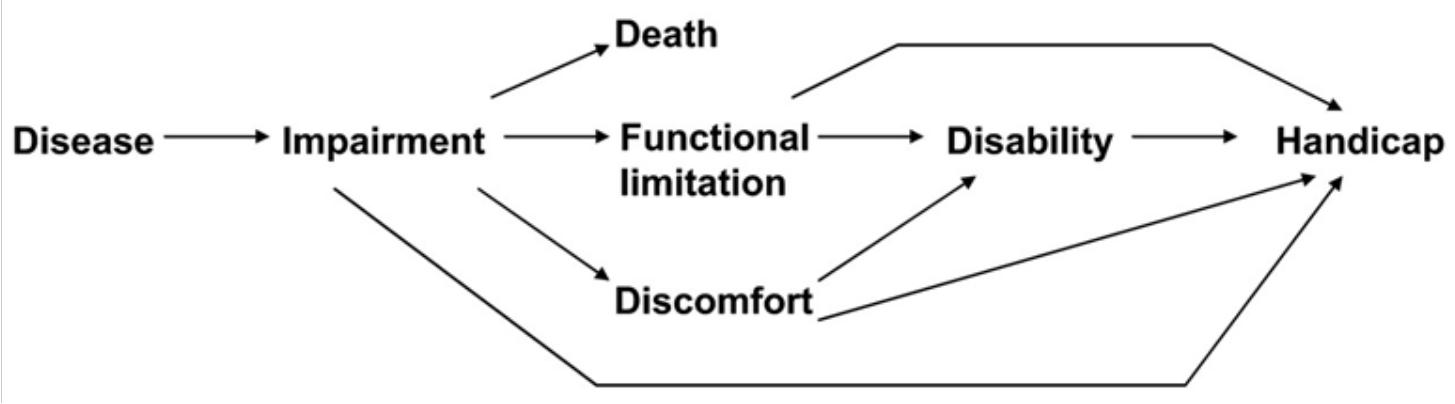

Figure 3

\section{Impact of orthodontic treatment on OHRQoL}

One of the main objectives of modern dental operative procedures is to improve patient quality of life in all its possible aspects. However, patient expectations before, during and after treatment are known to differ greatly. Malocclusion is the most common oral disorder which can cause negative impacts on social life and self-confidence and may be greatly associated with negative psychological connotations. ${ }^{7}$ Orthodontic treatment of a malocclusion from a purely clinical perspective may not address patients' concerns. Patients and their parents have been shown to share similar expectations of orthodontic treatment in most aspects, although parents seem to have more realistic expectations in their estimated duration of treatment at the initial visit. Ethnicity was shown to significantly influence expectations for the outcome of orthodontic treatment, and this may relate to differences in the patients' and parents' assessment of the outcome of care. ${ }^{8}$ Some researchers have shown that orthodontic treatment using fixed appliances resulted in a significantly improved quality of life after two years of treatment. ${ }^{9,10}$ On the other hand, other authors concluded that orthodontic treatment using fixed appliances significantly worsen the OHRQOL scores during treatment, ${ }^{11}$ and 24 hours following their insertion. A study that used the short form of the Child Perceptions Questionnaire (CPQ11-14) was used to compare difference in terms of impact on daily quality of life during the treatment period in two groups of children who received functional appliances and headgear respectively. Subjects in both groups demonstrated lower OHRQOL scores in comparison to a control group..$^{12}$ Many evidences have investigated the way orthodontic treatment affects OHRQoL, researchers have found differences between treated and untreated patients, but scores tend to be skewed toward favorable quality of life, even among severe malocclusion cases. A study included 1,675 adolescents; its methodology was based on administration of two OHRQoL scales and malocclusion assessment with an objective measure, the Index of Orthodontic Treatment Need (IOTN) individuals who had completed orthodontic treatment stated fewer oral health impacts than their other participants who were presently under treatment ( 2 times less) and fewer than those who were never treated almost by one fold adolescent with high need of treatment (using the IOTN) reported 3 times more dental impacts on the OHRQoL measures than did young individuals with lower need. Children with acceptable or ideal occlusion and their parents reported higher OHRQoL than those with any degree of malocclusion, precisely children who had increased overjet $(>6 \mathrm{~mm}$ ) or anterior spacing more than $1.5 \mathrm{~mm}$ between adjacent teeth. ${ }^{13}$ Another investigation assessed the link between OHRQoL and malocclusion severity among 430 children ages twelve to thirteen who varied in their extent of malocclusion. ${ }^{14}$ Using the Child Perceptions Questionnaire for elevento fourteen-year-olds (CPQ11-14), investigators observed a distinct OHRQoL gradient, with children in the "handicapping" category of malocclusion obtaining the highest (worst OHRQoL) scores and those in the "minor/no malocclusion" category scoring best. However, these differences arose only on the emotional and social well-being domains, not in oral symptoms or functional limitations (e.g., pain, difficulty chewing).

\section{Esthetics as a component of OHRQoL}

Facial and dental attractiveness signifies a vital element of quality of life for individuals seeking orthodontic treatment. Investigators have found that facial charm affects interpersonal success, predominantly in school and employment situations. Attractive children and adults generally have more encouraging judgments and academic and performance feedback than do unattractive patients. This in turn affects the self-confidence among those high in attractiveness. ${ }^{15}$ The appearance of teeth and the smile appearance are crucial components of facial charm. ${ }^{16}$ The media and society in general strengthen the concept that "beauty is good." Cinema and television actors or heroes have attractive teeth, in comparison to villains with crooked, broken and discolored teeth. However, these common stereotypes can generate self-criticism and dissatisfaction of young individuals who seek the perfection as it is perceived on television..$^{16,17}$

\section{The impact of malocclusion on quality of life}

Malocclusion is one of the most common oral disorders and its prevalence is high in most countries. ${ }^{18}$ The main reasons of malocclusion are a combination of genetic and environmental factors. The shift from a diet consisting of unrefined foods to one of softer processed foods has been reported to be a factor in the increase in the prevalence of malocclusion in modern times compared to prehistoric times. ${ }^{19}$ It is reported that malocclusion may be the cause of pain in traumatic overbite cases leading to a poorer quality of life (Gieger, 2001). Increased overjet may have a significant effect on QOL of individual, it is reported that individuals with over jets greater than $3 \mathrm{~mm}$ were two and half times more at risk to trauma than individual with normal over jet (Petty \& Tarsitani). On the other hand early treatment can improve the quality of life and self-esteem of the patient who will have less negative social experiences. ${ }^{20}$

\section{Oral health related quality of life and periodontal disease}

Periodontal health is one of the key factors in the survival of teeth; any deterioration in the health of periodontium will lead to the 
eventual loss of teeth. . If teeth are lost the average ratio of anterior maxillary residual ridge resorption to anterior mandibular residual ridge resorption was 1:4. On the average, residual ridge resorption is greater in the mandible than in the maxilla, the reverse may be true in any given patient who comes for treatment, each patient should have tailored treatment plan. ${ }^{20}$ Periodontal disease is the second commonest oral health problem, affecting $10-15 \%$ of the world population. ${ }^{21}$ Elderly patient institutionalized in Malta had poor oral health in comparison to those in rest of Europe this is because patient in Malta had barriers hindered them to access the health care system. ${ }^{22}$ Aggressive periodontitis worsens the quality of life of susceptible individuals. ${ }^{23}$ Patients who underwent non-surgical treatment for periodontal disease showed an improved quality of life. Dental caries considered the most common dental disease affecting $20-30 \%$ of the children and adolescents in United States (Center disease control and prevention, 2011). Dental caries may be associated with painful episodes and missed days from school as well as social embarrassments and dysfunction. ${ }^{24}$ this may result in a negative influence on quality of life and reduced mental and psychosocial ability ${ }^{25}$ Children with early childhood caries had significantly worse oral health related quality of life than caries free children; one addition they experienced pain, psychological, mental, social, or functional impairments. ${ }^{26}$ The same impact of caries on the oral health-related quality of life was reported in elderly institutionalized adults. ${ }^{22}$

\section{Assessment methods for measuring OHRQoL}

There are two broad categories used for assessment and evaluation of OHRQOL, some being generic measures and others diseasespecific. The generic measures can be applied to a number of disorders/ disease and evaluate the impact on QOL, while the disease-specific measure evaluates disorder impact on the QOL using distinct tools. However, some researchers pointed that it is not appropriate to use generic measures for the assessment of OHRQoL in people suffering from oral disorders or orofacial syndromes since these generic tools do not accurately evaluate such problems specifically, and as a result the QOL evaluation will not be sensitive nor accurate. ${ }^{27}$ Disease specific evaluation measures have more advantages over the generic tools. They were developed for specific conditions which increase the sensitivity compared to generic instruments. ${ }^{6}$ However it was noted that disease-specific instruments may focus too narrowly on symptoms so that they fail to record some broader domains included in generic instruments. Many tools were advocated to study the oral health-related quality of life. The Geriatric Oral Health Assessment Index (GOHAI) (later knows as the General Oral Health Assessment Index) estimates the patient-reported oral functional problems. It also estimates the degree of psychosocial impact associated with oral diseases, and is used to evaluate the effectiveness of dental treatment. The measure, based on a patient-centered definition of oral health for older adults, including components such as no pain to severe pain and infection, and the patient's ability to function in society. ${ }^{28}$

\section{OHIP (oral health impact profile)}

The Oral Health Impact Profile OHIP (Oral Health Impact Profile) is widely used to evaluate the OHRQOL; the nature of questions used in OHIP gives it many advantages as an assessment tool. There are seven variable dimensions covering all quality of life-affecting circumstances of a person, and suitable for individuals belonging to various society levels. ${ }^{29}$ The OHIP is a very technically sophisticated tool to measure OHRQOL. ${ }^{19}$ It was designed to study the quality of life of old people; it has been used in many fields like prosthodontics and periodontics ${ }^{22}$ and subsequently modified to be used in orthodontics. ${ }^{23}$ OHIP was developed by Spencer \& Slade ${ }^{34}$ in South Australia. OHIP originally was developed to provide a measurement to dysfunction, discomfort and disability, to assess the burden of disease and the effectiveness of health services in reducing the patient suffering. ${ }^{33}$ The original version of OHIP was made of 49-statement questionnaire divided into 7 sub-sections based on oral health model by Locker ${ }^{33}$ which cover different areas such as functional limitation, pain, psychological discomfort, physical disability, psychological disability, social disabilities and handicap. Locker conceptual framework was based on the World Health Organization classification on the impact of disease starting from internal symptoms, to disability, ranging to a handicap that may adversely affect work. The statements used in the OHIP Survey were asked to 64 dental patients to evaluate the impact of oral disease on their quality of life. The result was 535 statements which were re-evaluated and the net result was 46 questions, three statements were added more to cover handicap dimensions, which resulted in OHIP $49 .{ }^{35}$ Each statement is answered by one of 5 responses in the form of a Likert scale coded from 1 to 5 (Table 1). Following completion of the questionnaire, the codes are summed up and the result will indicate the impact of the problem on individual life or by use developed weights for each response category.

Table I

\begin{tabular}{ll}
\hline OHIP translations & Authors \\
\hline OHIP Arabic version & Al-Jundi MA et al. ${ }^{38}$ \\
OHIP Persian Version & RavaghiV et al. ${ }^{37}$ \\
OHIP Greek version & Papagiannopoulou et al. ${ }^{39}$ \\
OHIP Maltese version & Santucci D et al. ${ }^{22}$ \\
\hline
\end{tabular}

\section{OHIP was used to evaluate different aspects of epidemiological studies}

a. In people with poor oral health, such as having low number of teeth and carious lesion, periodontal pocket and gingival recessions the OHIP scores are high. ${ }^{19}$

b. People who don't visit the dentist regularly and have low socioeconomic status, OHIP are high. ${ }^{30}$

OHIP reliability was assessed in Australia (Adelaide) and Canada. The Australian assessment was on a sample of 122 patients aged from 60 and above, cross sectional results were used to create Cronbach Alpha coefficient for reliability ranged between 0.7-0.8. The Canadian assessment was done on people of age 50 and above, in across sectional study; the Cronbach Alpha coefficient for reliability was also between (0.8-0.9). Both resulted in good reliability. ${ }^{34}$ Other forms of OHIP exist. All have been scientifically tested and include: OHIP 20 which was originally designed for edentulous patients and the POST-OHIP-13 which was derived from OHIP 20 .36. A short version of OHIP-49 has been introduced (OHIP 14) which has been shown to be a very efficient tool in estimation of quality of life, with high sensitivity. ${ }^{36}$ OHIP 14 was translated to many languages as explained in Table 1. ${ }^{37-39}$

\section{Conclusion}

Oral health-related quality of life (OHRQoL) has an important impact on the clinical practice of dentistry and dental research. 
OHRQoL is a multidimensional paradigm that involves a subjective assessment of the individual's oral health, functional well-being, emotional well-being, expectations and satisfaction with care, and sense of self. Further researches needed in this domain to improve the quality of data that can enable researchers to draw solid conclusions. ${ }^{40-55}$

\section{Acknowledgments}

None.

\section{Conflicts of interest}

The authors declare there is no conflict of interest.

\section{References}

1. Rosser R. The history of health related quality of life in $10^{1} / 2$ paragraphs $J R$ Soc of Med. 1993;86(6):315-318.

2. Pennacchini M, Bertolaso M, Elvira MM, et al. A brief history of the Quality of Life: its use in medicine and in philosophy. La Clinica Terapeutica. 2011;162(3):e99-e103.

3. DHHS. Oral health in America: a report of the Surgeon General. US Department of Health and Human Services and National Institute of Dental and Craniofacial Research. Rockville, MD: National Institutes of Health. 2000.

4. Jokovic A, Locker D, Guyatt G. How well do parents know their children? Implications for proxy reporting of child health-related quality of life. Quality of Life Research: An International Journal of Quality of Life Aspects of Treatment, Care and Rehabilitation. 2004;13(7):1297-1307.

5. Gift HC, Atchison KA, Dayton CM. Conceptualizing oral health and oral health-related quality of life. Soc Sci Med. 1997;44(5):601-608.

6. Sischo L, Broder HL. Oral health-related quality of life: what, why, how, and future implications. J Dent Res. 2011;90(11):1264-1270.

7. Masood Y, Masood M, Zainul NNB, et al. Impact of malocclusion on oral health related quality of life in young people. Biomed Central. 2013;11:25.

8. Sayers MS, Newton JT. Patients' expectations of orthodontic treatment: Part 2-findings from a questionnaire survey. J Orthod. 2007;34(1):25-35.

9. Navabi N, Farnudi H, Rafiei H, et al. Orthodontic Treatment and the Oral Health-Related Quality of Life of Patients. J Dent (Tehran). 2012;9(3):247-254.

10. Feu D, Miguel JAM, Celeste RK, et al. Effect of orthodontic treatment on oral health-related quality of life. The Angle Orthodontist. 2013;83(5):892-898.

11. Costa A, Ferreira M, Serra Negra J, et al. Impact of wearing fixed orthodontic appliances on oral health-related quality of life among Brazilian children. J Orthod. 2011;38(4):275-281.

12. Kadkhoda S, Nejat S, Shirazi M. Comparison of oral-health-related quality of life during treatment with headgear and functional appliances. Int J Paediatrc Dent. 2011;21(5):369-373.

13. Sayers MS, Newton JT. Patients' expectations of orthodontic treatment: Part 2-findings from a questionnaire survey. J Orthod. 2007;34(1):25-35.

14. Foster Page LA, Thomson WM, Jokovic A, et al. Validation of the child perceptions questionnaire (CPQ11-14). J Dent Res. 2005;84(7):649-652.

15. Langlois J, Kalakanis L, Rubenstein A, et al. Maxims or myths of beauty? A meta-analytic and theoretical review. Psychol Bull. 2000;126(3):390423.
16. Thompson L, Malmberg J, Goodell N, et al. The distribution of attention across a talker's face. Discourse Process. 2004;38(1):145-168.

17. Johal A, Cheung MH, Marcenes W. The impact of two different malocclusion traits on quality of life. Br Dent J. 2007;33:1-4.

18. Hagg U, McGrath C, Zhang M. Quality of Life and Orthodontic Treatment Need Related to Occlusal Indices. Dental Bulletin. 2007;12(10):8-12.

19. Jokovic A, Allison P, Locker D, et al. A cross-cultural comparison of Quality of Life Regarding Patients with Periodontal Disease in Iasi, Romania. 1995.

20. O Brien K, Wright JL, Conboy FM, et al. Effectiveness of early orthodontic treatment with the Twin-block appliance: a multicenter, randomized, controlled trial. Part 2: Psychosocial effects. Am J Orthod Dentofacial Orthop. 2003;124(5):488-494.

21. Petersen E, Ogawa H. Strengthening the prevention of periodontal disease: the WHO approach. J Periodontol. 2005;76(12):2187-2193.

22. Suntucci D, Camelleri L, Attard N. Development of a Maltese Version of Oral Health-Associated Questionnaire: OHIP-14, GOHAL and the Denture Satisfaction Questionnaire. The International Journal of Prosthodontics. 2014;27(1):44-49.

23. Grigoras Simona, Martu Silvia, Balcos Carina. Procedia - Social and Behavioral Sciences 2014;127:15-20.

24. Meulen MJ, John MT, Naeije M, et al. The Dutch version of the Oral Health Impact Profile (OHIP-NL): Translation, reliability and construct validity. BMC Oral Health. 2008;8:11.

25. Jackson JE, Fleckenstein M. An evaluation of some statistica techniques used in the analysis of paired comparison data. Biometrics. 1957;13(1):51-64.

26. Barbosa T, Claudia M, Marinês, et al. The relationship between oral conditions, masticatory performance and oral health-related quality of life in children Original Research Article. Archives of Oral Biology. 2013;58(9):1070-1077.

27. Filstrup SL, Briskie D, Da Fonseca M, et al. Early childhood caries and quality of life: child and parent perspectives. Pediatr Dent. 2003;25(5):431-440.

28. Jokovic A, Locker D, Guyatt G. What do children's global ratings of oral health and well-being measure? Community Dentistry and Oral Epidemiology. 2005;33(3):205-211

29. Atchison KA, Dolan TA. Development of the Geriatric Oral Health Assessment Index. J Dent Educ. 1990;54(11):680-687.

30. John MT, Patrick DL, Slade GD. The German version of the Oral Health Impact Profile-translation and psychometric properties. Eur J Oral Sci. 2002;110(6):425-433.

31. Slade GD, Spencer AJ. Development and evaluation of the Oral Health Impact Profile. Community Dent Health. 1994;11(1):3-11.

32. Tugwell P, Bennett KJ, Sackett D. Relative risks, benefits and costs of intervention. In: Warren KS, et al. editors. Tropical and geographic medicine. New York, USA: McGraw Hill; 1985:1097-1113.

33. Locker D. Measuring oral health: a conceptual framework. Community Dent Health. 1988;5(1):3-18

34. Jokovic A, Allison P, Locker D, et al. A cross-cultural comparison of oral health values. J Dent Res. 1997;78(2):643-649.

35. Lee IC, Sheih TY, Yang YH, et al. Individuals' perception of oral health and its impact on the health-related quality of life. Journal of Oral Rehabilitation. 2007;34(2):79-87. 
36. Montero J, López JF, Vicente MP, et al. Comparative validity of the OIDP and OHIP-14 in describing the impact of oral health on quality of life in a cross-sectional study performed in Spanish adults. Med Oral Pathol Oral Cir Bucal. 2011;16(6):e816-e821.

37. Ravaghi V, Farrahi Avval N, Locker D, et al. Validation of the Persian short version of the Oral Health Impact Profile (OHIP-14). Oral Health Prev Dent. 2010;8(3):229-235.

38. Aljundi MA, Szentpetery A, John MT. An Arabic version of the Oral Health Impact Profile: translation and psychometric properties. Int Dent J. 2007;57(2):84-92.

39. Papagiannopoulou V, Oulis CJ, Papaiannou W, et al. Validation of a Greek version of the oral health impact profile (OHIP-14) for use among adults. Health Qual Life Outcomes. 2010;10:7.

40. Brook PH, Shaw WC. The development of an index of orthodontic treatment priority. Eur J Orthod. 1989;11:309-320.

41. Christie M, French D, Sowden A, et al. Development of child-centered, disease-specific questionnaires for living with asthma. Psychosom Med. 1993;55(6):541-548.

42. Nguyen QV, Bezemer PD, Habets L. A systematic review of the relationship between overjet size and traumatic dental injuries. Eur $J$ Orthod. 1999;21(5):503-515.

43. Palma PV, Caetano PL, Leite ICG. Impact of Periodontal Diseases on Health-Related Quality of Life of Users of the Brazilian Unified Health System. International Journal of Dentistry. 2013:1-6.

44. Richmond S, Shaw WC, O'Brien KD, et al. The development of the PAR Index (Peer Assessment Rating): reliability and validity. Eur J Orthod. 1922;14:125-139.

45. Feu D, De Oliveira BH, De Oliveira Almeida MA, et al. Oral healthrelated quality of life and orthodontic treatment seeking. American Journal of Orthodontics and Dentofacial Orthopedics: Official Publication of the American Association of Orthodontists, its Constituent Societies. American Board of Orthodontics. 2010;138(2):152-159.
46. Gilson BS, Gilson JS, Bergner M, et al. The sickness impact profile. Development of an outcome measure of health care. Am J Pub Health. 1975;65(12):1304-1310.

47. Hunt SM, McEwan J, McKenna SP. Measuring health status. London, UK: Croom Helm; 1986.

48. Kleinman A. The illness narratives: suffering, healing, and the human condition. New York, USA: Basic Books; 1988:1-304.

49. Kok YV, Mageson P, Harradine NW, et al. Comparing a quality of life measure and the Aesthetic Component of the Index of Orthodontic Treatment Need (IOTN) in assessing orthodontic treatment need and concern. J Orthod. 2004;31(4):312-318.

50. Locker D, Jokovic A, Clarke M. Assessing the responsiveness of measures of oral health-related quality of life. Community Dentistry and Oral Epidemiology. 2004;32(1):10-18.

51. Locker D. Disparities in oral health-related quality of life in a population of Canadian children. Community Dent Oral Epidemiol. 2007;35(5):348356.

52. Luther F, Layton S, McDonald F. Orthodontics for treating temporomandibular joint (TMJ) disorders. Cochrane Database Syst Rev. 2010;7:CD006541.

53. Slade GD. Derivation and validation of a short-form oral health impact profile. Community Dent and Oral Epidemiol. 1997;25(4):284-290.

54. Strauss RP, Hunt RJ. Understanding the value of teeth to older adults: Influences on the quality of life. JADA. 1993;124(1):105-110.

55. Wilson IB, Cleary PD. Linking clinical variables with health-related quality of life, A conceptual model of patient outcomes. JAMA. 1995;273(1):59-65. 